\title{
eNIGMA e M-Learning: jogo educativo trabalhando o raciocínio lógico através de dispositivos móveis
}

\author{
Andreia Rosangela Kessler Mühlbeier ${ }^{1}$ \\ Patricia Mariotto Mozzaquatro ${ }^{1}$ \\ Leander Cordeiro de Oliveira $^{2}$ \\ Taísa Belzarena Monteiro ${ }^{2}$ \\ Vinícius Lopes ${ }^{2}$
}

\begin{abstract}
Resumo: O raciocínio lógico é uma necessidade em estudantes de diferentes áreas. A utilização da ferramenta eNIGMA visa a busca do pensamento de forma crítica acerca de conteúdos com base em critérios e princípios logicamente validados. Observando a contemporânea e crescente necessidade por mobilidade, a disponibilidade de ferramentas educacionais adaptadas torna-se necessária e uma alternativa na busca por conhecimento. O objetivo deste trabalho é apresentar o desenvolvimento e a aplicação do jogo eNIGMA utilizando o software Hot Potatoes, considerando seu acesso através dos conceitos de M-Learning. Em síntese, apresentar a perspectiva lúdica aliada à mobilidade é eficiente e torna a utilização consideravelmente mais facilitada.
\end{abstract}

Palavras-chave: Hot Potatoes. Jogos educacionais. M-Learning.

\begin{abstract}
The rationale reasoning is a need in students from different areas. Use of eNIGMA tool aims to search of thinking critically about content based on criteria and principles logically validated. Noting the increasing need for mobility nowadays, the availability of appropriate educational tools is necessary and an alternative in quest for knowledge. The objective of this paper is to present the development and application of eNIGMA using Hot Potatoes software, considering the access through the concepts of M-Learning. In synthesis, playful perspective allied to mobility is efficient and makes the utilization considerably easier.
\end{abstract}

Keywords: Educational games, Hot Potatoes. M-Learning.

\section{Introdução}

Os jogos digitais aparecem nesse contexto como um recurso didático que contém características que podem trazer uma série de benefícios para as práticas de ensino e aprendizagem. Então, por que não considerar as preferências do aluno? Por que não se utilizar do computador, mais precisamente dos jogos computadorizados, como instrumento mediador do processo de ensino/aprendizagem?

No presente artigo, serão apresentados o desenvolvimento e a aplicação do jogo educacional eNIGMA utilizando o software Hot Potatoes. Os tópicos explorados serão os seguintes: A seção 2 apresenta um estudo sobre a informática na educação. A seção 3 é dedicada aos paradigmas de educação a distância E-Learning e MLearning. A seção 4 trata de jogos educacionais e a seção 5 de ferramentas para a construção desses jogos. $O$ Jogo eNIGMA é apresentado na seção 6 e os resultados e discussões são apresentados na seção 7. Por fim, a seção 8 apresenta a conclusão do artigo e na sequência são apresentadas as referências.

\footnotetext{
${ }^{1}$ UFSM - Universidade Federal de Santa Maria - Av. Roraima, 1000 - Santa Maria (RS) - Brasil.

\{andreiamuhlbeier@yahoo.com.br, patriciamozzaquatro@gmail.com\}

${ }^{2}$ Curso de Ciência da Computação, UNICRUZ - Universidade de Cruz Alta - Cruz Alta (RS) - Brasil.

\{leander_dewon@yahoo.com.br,taisa.belzarena@hotmail.com,vin.lopes159@gmail.com\}
}

http://dx.doi.org/10.5335/rbca.2012.2450

Revista Brasileira de Computação Aplicada (ISSN 2176-6649), Passo Fundo, v. 4, n. 2, p. 92-102, out. 201292 


\title{
2 Informática na educação
}

Com o rápido e aparente avanço da tecnologia, ficou impossível manter as crianças longe do computador, pois elas crescem vendo essa tecnologia em todos os lugares, e também querem ter contato com tal ferramenta que tanto encanta os jovens e adultos [17].

O problema é que, principalmente no Brasil, não se tem ainda em todos os lugares a prática de aliar a construção do conhecimento ao uso das novas tecnologias e isso começa em casa, onde os pais de crianças menores de dez anos utilizam o computador apenas como uma forma de manter os filhos entretidos, com joguinhos que prendam suas atenções quando estão fora da escola, sendo esse, às vezes, o único contato que eles têm com o computador.

Algumas escolas já adotam a informática como disciplina da grade curricular, mas separadamente das outras, com o pensamento de que "português não se mistura com matemática", por isso informática deve ser aprendida longe das disciplinas tradicionais. Aos poucos esse conceito errôneo está mudando, estabelecendo-se a proposta de fazer a informática entrar no ritmo da interdisciplinaridade, servindo de alicerce para a construção do conhecimento de todas as disciplinas da grade curricular tradicional das escolas, através do uso dos computadores nas aulas do dia a dia ou mesmo com o uso de softwares educacionais adequados para cada disciplina.

Segundo Alves et al. [6],

\begin{abstract}
democratizar a informação não pode, assim, envolver somente programas para facilitar e aumentar o acesso à informação. É necessário que o indivíduo tenha condições de elaborar este insumo recebido, transformando-o em conhecimento esclarecedor e libertador, em benefício próprio e da sociedade onde vive.
\end{abstract}

À mesma medida que cresce a tecnologia, cresce também a vontade dos jovens em conhecer inovações, por isso, em muitos casos, temos jovens que não gostam e não conseguem ficar um turno inteiro dentro de uma sala de aula. Eles querem estar em contato instantâneo com a informação, novas tecnologias e as rápidas e constantes mudanças do mundo. É nessa brecha que as novas práticas de aliar a informática com a educação devem encontrar espaço, fazendo o aluno até então considerado "ouvinte" virar "construtor" do seu próprio conhecimento, em um processo em que ele não senta em sua classe e apenas escuta o professor explicar o que será cobrado na prova, mas usa a informática para buscar conhecimento em torno de toda a World Wide Web, filtrando o que vai lhe ajudar a absorver o conteúdo que é proposto em sala de aula e/ou no ambiente virtual de aprendizagem.

\section{Ambientes de ensino e jogos eletrônicos}

Apesar da crescente procura por informatização, instituições de ensino ainda têm dificuldades em integrar aprendizado a recursos computacionais. Segundo Oliveira et al. [15], atualmente, mesmo com o grande crescimento da área de tecnologia e o barateamento de recursos de informática, escolas e professores têm dificuldades em integrar toda a nova realidade que a tecnologia pode proporcionar. Existem tablets, netbooks, smartphones com valores reduzidos e que poderiam ser utilizados como complementos ou até mesmo modificar de maneira bastante complexa o processo de ensino e aprendizagem.

A realidade descrita poderia ser modificada, por exemplo, a partir do momento em que diferentes disciplinas passam a integrar o processo de aprendizagem com recursos computacionais, não tratando a informática como uma disciplina separada e que deve ser aprendida de maneira isolada e sim como algo interdisciplinar, presente na realidade dos alunos. Segundo Aranha [3], o conhecimento acontece através da manipulação e conexão de informações e não da simples memorização. A informática pode facilitar as questões descritas.

Uma possibilidade para trabalhar informática na educação envolve disciplinas ou cursos que se caracterizam por aulas não presenciais. Ambientes que lidam com esse contexto se encaixam no modelo de 
eletronic learning (e-Learning). Nela são usados computadores com acesso à internet para a multiplicação do conhecimento. Assim, segundo Xu [18], existem mais opções que na educação tradicional, justamente pela possibilidade de disponibilizar materiais diversos e apresentar os conteúdos de maneira mais interativa e dinâmica.

A partir do uso de ambientes e-Learning, estudantes podem utilizar ambientes virtuais de aprendizagem (AVAs), por exemplo, para a interação, esclarecimento de dúvidas, elaboração de exercícios, leitura de materiais etc. O conteúdo é administrado por professores que devem estar aptos para trabalhar nesse tipo de ambiente. Segundo Alves et al. [2] esse formato de ensino começou a se popularizar a partir da década de 1990 com o surgimento de grandes instituições de ensino a distância espalhadas pelo mundo e está bastante disseminado no meio acadêmico atualmente, mas ainda enfrenta dificuldades para ser utilizado no ensino médio, fundamental, e em escolas de um modo geral.

Outro recurso que pode promover a educação de maneira diferenciada são os jogos eletrônicos digitais. Aranha [3] descreveu a importância de jogos eletrônicos no processo de aprendizagem através de características como a imersão e interatividade, o que torna tais ferramentas bastante motivacionais e atrativas aos estudantes. Tais jogos podem ser oferecidos de diversas maneiras, inclusive de maneira conjunta a AVAs ou outros ambientes de ensino, integrando-se assim a toda a realidade tecnológica descrita e tornando o aprendizado mais proveitoso, intuitivo, dinâmico, enfim, facilitado ao aluno e ao professor. Albuquerque, Azevedo e Cruz [1] observaram que o raciocínio de crianças e jovens é incentivado e desenvolvido quando o jogador precisa tomar decisões, gerenciar a narrativa, escolher e priorizar situações na busca por objetivos, ou seja, pode ser dito que se pode aprender a pensar jogando.

Segundo Alves et al. [2], para cursos específicos, o uso de games agiria no sentido de trabalhar com desafios cognitivos que fariam com que os alunos imergissem em um ambiente e assim trabalharia com hipóteses, testes, criação de possibilidades para solucionar problemas e ainda, na maioria das vezes, com a interação com um grupo e seus professores na busca do objetivo de determinado desafio.

Ao analisar todo o âmbito que envolve a situação atual do ensino presencial das escolas, o ensino a distância das universidades, jogos eletrônicos e todos os recursos tecnológicos e de informática hoje disponíveis, é possível perceber o quanto a integração desses fatores poderia trazer grandes benefícios para a educação, principalmente em lugares onde os índices relacionados à educação seguem padrões reduzidos.

\section{$4 \quad$ Eletronic learning e mobile learning}

A necessidade tecnológica tem avançado a passos largos e já se tornou difícil fugir dela, tendo destaque sua enorme contribuição, tornando desde as pequenas tarefas diárias (ensino e aprendizagem, por exemplo) até momentos mais complexos (na medicina ou aplicações financeiras) mais fáceis e rápidos ao serem realizadas com a utilização de computadores, celulares, tablets.

Como já dito anteriormente, assim como cresce o acesso à tecnologia de informação, cresce também a necessidade de aliar a educação a essas ferramentas inovadoras. Para suprir tal necessidade, encontrou-se como solução a eletronic learning (E-Learning), onde são usados computadores e acesso à internet para a multiplicação do conhecimento. Esse modelo faz com que a educação on-line tenha mais opções do que a educação tradicional [18], justamente por disponibilizar materiais diversos e apresentar os conteúdos de maneira mais interativa e dinâmica.

Segundo Oliveira e Mozzaquatro [14], apesar da facilidade proporcionada pelo modelo E-Learning, a restrição do usuário em relação à mobilidade geográfica acaba se tornando um empecilho de um processo de ensino/aprendizagem contínuo, justamente pela necessidade do usuário utilizar seu computador ou notebook de maneira estática. Através dessas necessidades do usuário, Weiser [19] descreve que não mais o usuário deve se adaptar à tecnologia, mas, de maneira contrária, as tecnologias devem se adaptar às necessidades do usuário. Considerando tais fatos e a caracterização da computação móvel através do processamento computacional aliado à mobilidade, exposto por Augustin et al. [4], surge um novo paradigma, a Mobile Learning (M-Learning), reunindo os conceitos de E-Learning e computação móvel, trazendo ao aluno novas perspectivas em relação à utilização de AVAs com a liberdade de locomoção e deslocamento.

A prática de ler em dispositivos móveis já está bastante disseminada, seja na leitura de livros digitais, de páginas da internet ou das as notícias do dia a caminho do trabalho. Mas já não basta levar somente diversão para dentro dos celulares, smartphones e tablets. Pesquisadores e desenvolvedores já dedicam-se a aliar tecnologia e

Revista Brasileira de Computação Aplicada (ISSN 2176-6649), Passo Fundo, v. 4, n. 2, p. 92-102, out. 201294 
educação, por meio de softwares educacionais nos quais o usuário pode acessar suas apostilas, jogos, exercícios, fóruns, chats, e-mails e vídeo-aulas de maneira integrada em um ambiente online que permita aos professores e alunos um grande nível de interação (os AVAs) em qualquer lugar e a qualquer hora, o que facilitaria a administração das tarefas diárias dos usuários com pouco tempo para estudar, por exemplo.

O chamado Mobile Learning ou m-Learning, por trazer tamanha facilidade e benefícios ao usuário, está no foco de pesquisadores como parte de um modelo de aprendizado integrado, caracterizado pelo uso de dispositivos de comunicação sem fio, de forma transparente e com alto grau de mobilidade [16]. Assim surgiu o desenvolvimento da ferramenta eNIGMA descrita neste trabalho, aliada à computação móvel na busca por facilidade no acesso a conteúdos que trabalham o raciocínio lógico de estudantes em diferentes áreas de interesse.

\section{Jogos educacionais}

$\mathrm{Na}$ era da tecnologia, o expressivo interesse dos jovens pelos jogos digitais começa geralmente na infância, onde os pais, para manter seus filhos seguros e entretidos dentro de casa, os colocam em frente ao computador ou videogame, fazendo despertar a prática de usar a tecnologia para diversão [9].

Essas mesmas crianças, contudo, frequentam uma escola convencional e acostumam-se com a educação convencional em sala de aula, com quadro negro, cadernos e livros, o que pode lhes parecer frustrante, fazendo com que contem os minutos para sair da aula e correr para a frente da televisão ou do computador, o que é, para eles, realmente mais interessante e divertido.

Para mudar essa cena, temos hoje o apoio dos jogos digitais educacionais, que visam ensinar e divertir de maneira simultânea, algo que dificilmente ocorreria com as práticas convencionais de ensinar.

Os jogos digitais educacionais ainda são pouco utilizados por encontrar algumas dificuldades, tanto em sua construção como software, como na inserção deles na vida escolar, já que se trata de quebrar paradigmas relacionados à forma tradicional da educação mundial. Segundo Elman e Werba [8], a dificuldade da inserção dos jogos digitais educativos nas escolas se dá pelo fato de que desenvolvedores fazem jogos divertidos e atraentes deixando um pouco de lado o objetivo da aprendizagem, enquanto os pedagogos focam-se no objetivo didático e acabam criando jogos chatos para os alunos.

Engana-se quem acredita que os jogos digitais educacionais têm como vantagem apenas auxiliar no aprendizado das disciplinas escolares, pois trata-se de uma série de benefícios causados por tais softwares, e que precisam ser reconhecidas como agentes facilitadores no desenvolvimento da criança.

O principal ponto que conquista as crianças nos jogos digitais educacionais é a motivação, pois, como em qualquer outro jogo, elas precisam ser desafiadas a alcançarem os objetivos e a ir cada vez mais longe, pois, como disseram Balasubramanian e Wilson [5], conseguem provocar o interesse e motivam estudantes com desafios, curiosidades, interação e fantasia. Porém, podem-se notar vários outros pontos positivos com o uso desses softwares, como a facilidade de ensinar em vários níveis e áreas da educação, bem como definiram Mitchell e Savill-Smith [13] quando disseram que os jogos colocam o aluno no papel de tomador de decisão e o expõem a níveis crescentes de desafios para possibilitar uma aprendizagem através da tentativa e erro.O aluno também pode desenvolver mais rápido suas habilidades cognitivas e, segundo Gros [11], os jogos promovem o desenvolvimento intelectual, já que para vencer os desafios o jogador precisa elaborar estratégias e entender como os diferentes elementos do jogo se relacionam.

\section{Ferramentas para a construção de jogos educacionais}

O computador não é um instrumento que ensina o aprendiz, mas pode ser uma ferramenta com a qual o professor proporciona momentos de aprendizado através da criação de material a ser explorado pelos alunos. Segundo Freire [10], o ensino não é apenas o ato de transferir conhecimento, mas também a criação de possibilidades para a própria produção ou construção. 
Uma das características do computador é o fato de não possuir apenas uma forma de uso, mas várias possibilidades, através de softwares prontos ou material elaborado pelo próprio educador, visando alcançar um determinado objetivo, produção essa que vem auxiliar na problematização, que desafia e motiva à aprendizagem.

Conforme Haetinger:

Para o uso das novas tecnologias aplicadas à educação, deve-se considerar uma nova postura, tanto do professor como dos alunos. O aluno, através do uso dessas ferramentas, comprometese muito mais com o seu aprendizado (o que não acontecia no ensino tradicional) [12].

O trecho da reportagem citado abaixo traz colocações significativas, pois segundo Elman e Werba:

\begin{abstract}
Além de oferecer aos alunos a oportunidade de contar com a ciência da Informática e manipular controles e linguagens, o grande objetivo do trabalho com os computadores, que tem sido perseguido ao longo desses anos, é o de apresentá-los como um dos tantos recursos didáticos significativos para o aprender, para a construção do próprio conhecimento, para o desenvolvimento individual [8].
\end{abstract}

Segundo Haetinger:

O caráter moderno e dinâmico das ferramentas tecnológicas deve ser associado às atividades e jogos criativos para a promoção de vivências que resultarão na construção de conhecimentos. Aplicando estes conceitos na descoberta da informática e para a inclusão digital, iremos além do desenvolvimento de habilidades para um melhor uso do computador, podendo também oportunizar um pensar único e vivências completas e ricas nas atividades de sala de aula [12].

O computador é uma ferramenta muito rica e que traz a possibilidade de criar aulas bastante interessantes, que façam com que o aluno aprenda através deste fascinante universo.

\title{
5.1 Ferramenta hot potatoes
}

Hot potatoes é um conjunto de seis ferramentas de autoria, desenvolvidas pela equipe da University of Victoria CALL Laboratory Research and Development, que possibilitam a elaboração de seis tipos básicos de exercícios interativos utilizando páginas Web para aplicações voltadas ao uso educacional.

A interatividade dos exercícios é obtida através do uso de JavaScript. As ferramentas de autoria admitem também caracteres acentuados, o que possibilitará a criação de exercícios em qualquer língua baseada no conjunto de caracteres do alfabeto romano, incluindo o francês, o alemão e outras línguas europeias.

O hot potatoes possibilita a elaboração de cinco tipos básicos de exercícios interativos usando páginas da Web: Quiz (módulo que realiza testes de múltipla escola e resposta simples), Jmix (sopa de palavras), JCross (palavras cruzadas) JMatch (exercícios de correspondências) e JClose (exercícios de preenchimento de espaço).

Existem três passos fundamentais para elaborar um exercício: a introdução dos dados (perguntas, respostas etc), a configuração do aspecto final (preparação dos nomes dos botões, as instruções e outras características de suas páginas Web) e a elaboração das páginas Web (organizar seus exercícios em páginas HTML).

\section{7 eNIGMA}

O jogo educacional eNIGMA integrou treze problemas de raciocínio lógico inspirados na série de jogos "Professor Layton", jogo de enigmas da plataforma Nintendo DS. As atividades propostas envolveram interação do usuário por meio de questões textuais respondidas em tempo determinado. 
O jogo eNIGMA ${ }^{3}$ pode ser acessado por diversos dispositivos móveis além de máquinas estáticas pelos seguintes navegadores: Internet Explorer, Google Chrome, Mozilla Firefox, dentre outros. Neste artigo, foi tratado o acesso por dispositivos móveis, somente. Conforme observado na Figura 1, o usuário tem acesso à página inicial que apresenta o jogo com o botão "iniciar". Em cada uma das atividades o software apresenta botões de ajuda que disponibilizam dicas para a resolução das questões. Vale lembrar que quando uma dica for acessada a pontuação, que é gerada para cada enigma, é reduzida. Existe, ainda, o botão "Soletrar", que soletra a resposta, fazendo assim a pontuação diminuir conforme as letras são reveladas. Estuda-se agora a possibilidade de exclusão deste botão de soletração, considerando que o botão de ajuda é suficiente nas dicas para a resolução.

Uma sucinta explicação da resolução somente é apresentada ao usuário mediante o acerto da questão. Caso o limite de tempo for alcançado, a questão não poderá ser respondida. Para o acesso ao próximo desafio, o botão "Próximo" está disponível em todas as atividades e pode ser usado a qualquer momento. A Figura 1 ilustra a tela inicial do jogo acessado através do dispositivo iPhone. A Figura 2 apresenta a atividade "Descubra o Dia", a mesma objetiva trabalhar a matemática aplicada ao raciocínio lógico e a interpretação de textos.

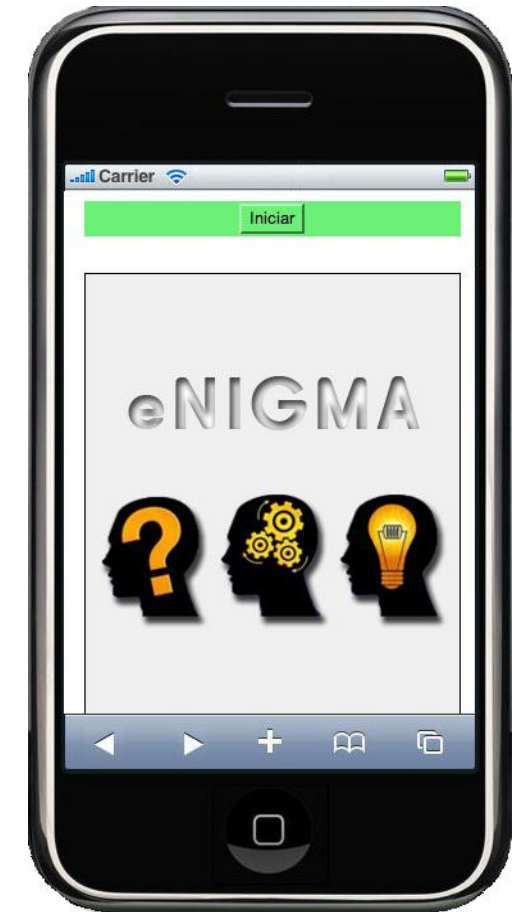

Figura 1: Tela inicial da ferramenta

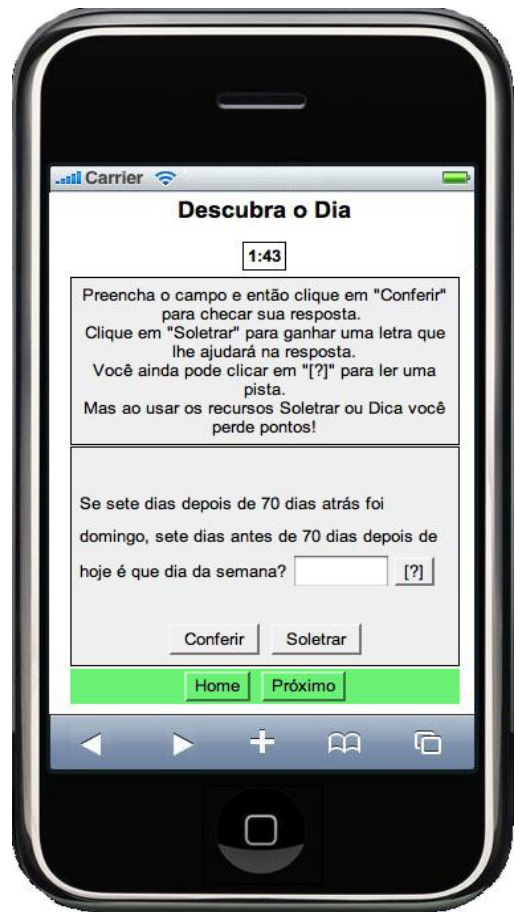

Figura 2: Atividade "Descubra o Dia"

${ }^{3}$ http://ideal.inf.br/moodle/enigma/ 


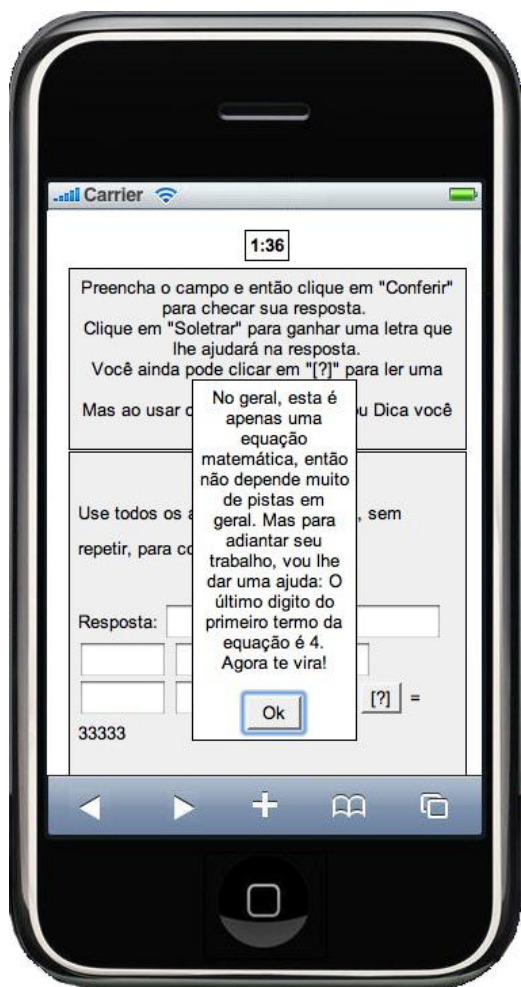

Figura 3: Atividade "Complete a equação" com recurso de ajuda

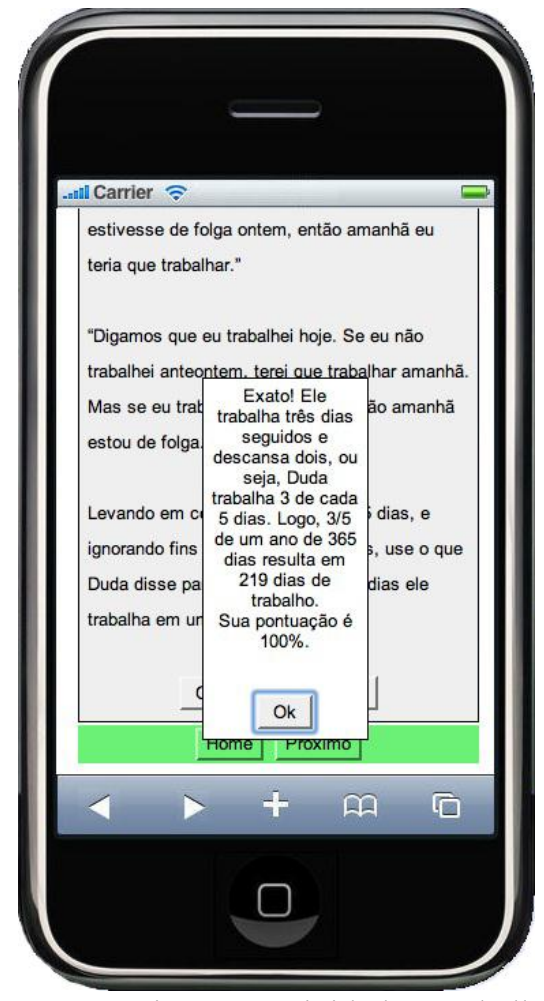

Figura 4: Atividade "Trabalho do Duda" com recurso de resolução

A Figura 3 apresenta uma equação matemática na qual o usuário deverá utilizar todos os algarismos de 1 a 9 sem repeti-los para completar a equação. Na imagem pode ser vista uma pequena janela de ajuda que dá dicas de resolução ao usuário. Já a Figura 4 aborda raciocínio lógico, interpretação de texto e matemática. A atividade visa à busca da resposta através de matemática básica. A tela de resolução mostrada na figura explana a maneira como o usuário chega ao resultado. 


\section{$8 \quad$ Resultados e discussão}

Ao concluir os estudos dos conceitos, dos paradigmas de ensino a distância e das ferramentas de desenvolvimento o software desenvolvido passou por um momento de testes com usuários para que esses pudessem avaliar aspectos importantes como acessibilidade, facilidade de uso, confiabilidade, dentre outros. O sistema foi utilizado por 11 acadêmicos do curso de Graduação em Ciência da Computação da Universidade de Cruz Alta (Unicruz) através de seus próprios dispositivos. Alguns dos utilizados foram o Sony Ericsson Xperia x10 Mini Pró com Android 2.1, o Nokia C3-00 com Symbian S40 através do navegador Opera Mini, o iPhone 3GS com sistema operacional iOS4.2, dentre outros.

Após os alunos interagirem com a ferramenta, foi aplicado um questionário avaliativo. Os resultados (em números) decorreram da compilação do formulário aplicado. Para a elaboração e disponibilização do questionário foi usada a ferramenta on-line Makesurvey ${ }^{4}$, que possibilita a criação de questionários on-line com questões em vários formatos e o acesso adaptado através para dispositivos móveis. Na Figura 5 observa-se que a maioria dos entrevistados $(73 \%)$ consideraram o tempo de resposta e a velocidade de execução aceitável. Acredita-se que a discordância dos 38\% deve-se ao fator de acesso através de dispositivos móveis.

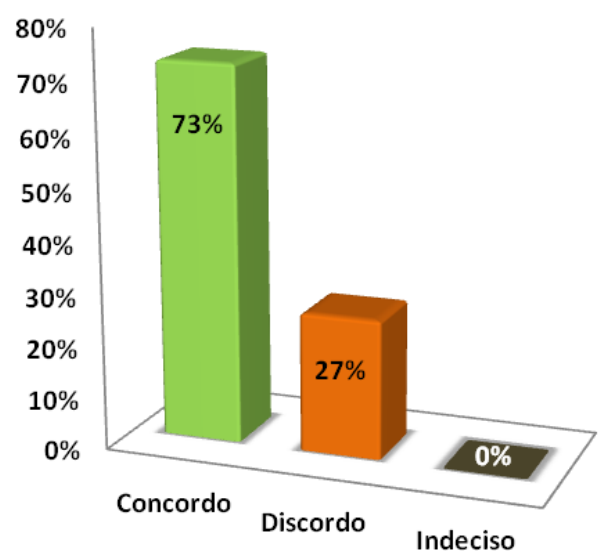

Figura 5: O tempo de resposta e velocidade de execução é aceitável?

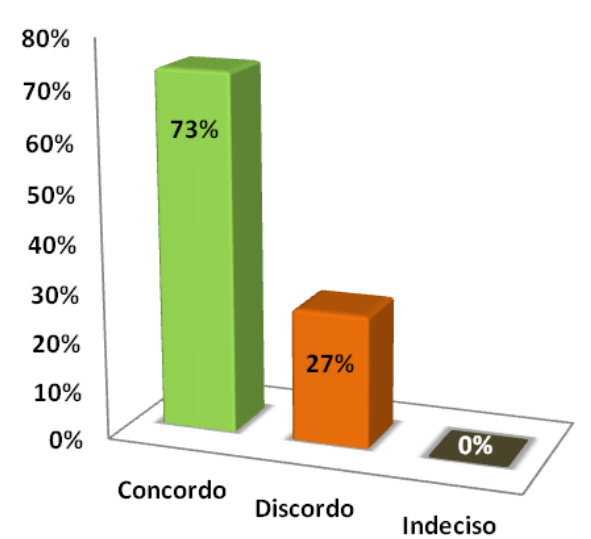

Figura 6: As ferramentas do sistema fazem o que o usuário deseja?

Na Figura 6 foi questionado aos usuários se as ferramentas do sistema atendem ao objetivo proposto, para o que se obteve resposta positiva $(73 \%)$.

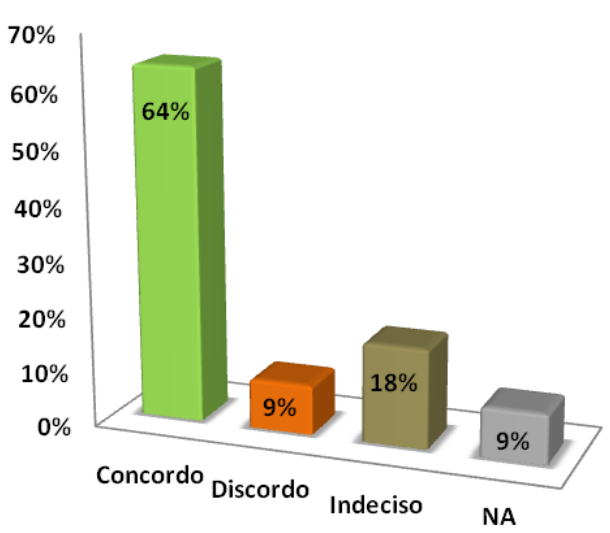

Figura 7: As instruções mostradas durante a evolução do Jogo ajudam o usuário na compreensão do Software?

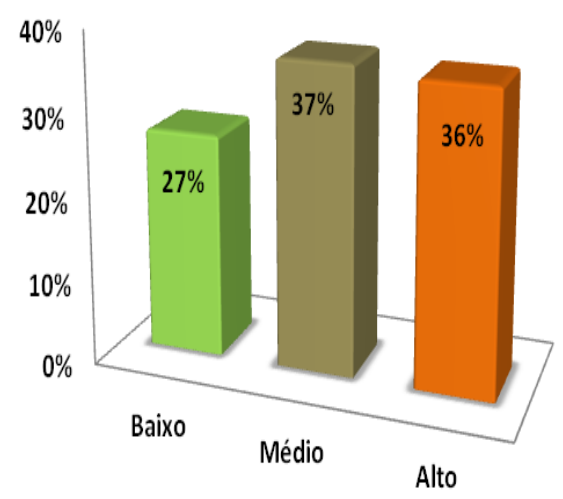

Figura 8: Durante a interação com o sistema qual o nível de dificuldade encontrado?

${ }^{4}$ Disponível em http://www.makesurvey.net/ 
Em relação às instruções apresentadas durante a execução das atividades (Figura 7), constatou-se que a maioria (64\%) concorda que o software disponibiliza as informações necessárias (ajuda, dicas, feedback da resposta, entre outros).

Relacionando o nível da dificuldade na interação com o software (Figura 8), 37\% respondeu que a dificuldade encontrada foi média, $36 \%$ (alta) e $27 \%$ (baixa). Acredita-se que a dificuldade encontrada deve-se à dificuldade dos enigmas, o tempo disponibilizado para sua resolução e ainda ao fato dos usuários não estarem muito familiarizados a acessar esse tipo de ferramenta através de dispositivos portáteis, cujas telas são reduzidas e os botões adaptados.

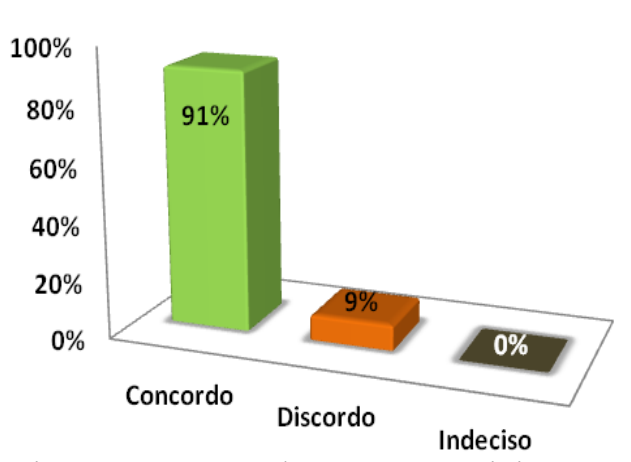

Figura 9: De acordo com sua opinião, o nível de qualidade apresentado pelo sistema em relação aos objetos de aprendizagem é valido?

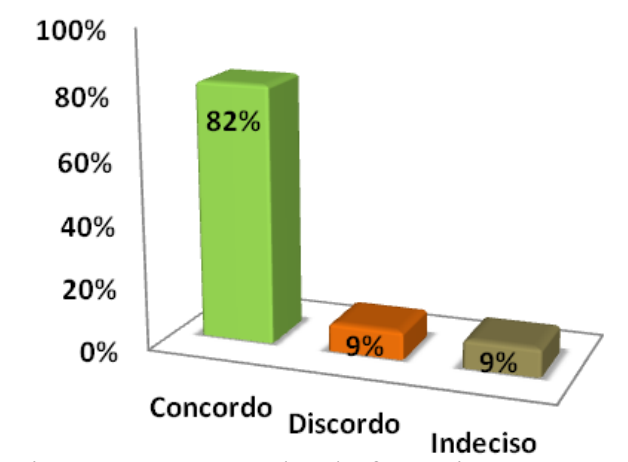

Figura 10: O tamanho da fonte, imagens e cores apresentadas facilitam a leitura?

Conforme observado na Figura 9, a maioria (91\%) apontou o nível de qualidade como válido sobre o sistema em relação aos objetos de aprendizagem.

Finalmente, pelo fato de a ferramenta estar sendo acessada através de dispositivos portáteis, foram questionados os recursos de texto, imagens e cores apresentados na tela. Na Figura 10 podemos constatar que esses foram considerados facilitadores na interação com o a ferramenta (82\%). Deve-se ressaltar que, conforme testes realizados pelos desenvolvedores, o sistema funciona na maioria dos browsers inclusive em diferentes dispositivos móveis.

\section{Considerações finais}

Jogos educacionais e ferramentas interativas bem projetadas podem ser criados e utilizados para unir práticas educativas com recursos multimídia em ambientes lúdicos portáteis a fim de estimular e enriquecer as atividades de ensino e aprendizagem em momentos ociosos dos estudantes e interessados.

Por fim, este trabalho não tem a pretensão de apresentar conclusões definitivas, ou fechadas, sobre o tema em questão. Procurou-se, antes de tudo, entender que o processo de ensino e aprendizagem aliado a tecnologias móveis alcança seus objetivos quando professor e aluno encontram-se dispostos a experimentar novas alternativas que promovam e justificam a aprendizagem.

Foi com grande interesse e curiosidade que constatamos, ao longo de todo o processo de desenvolvimento desse artigo, a existência de espaço para desencadear outras pesquisas nessa área tais como a inclusão de objetos de aprendizagem e jogos educacionais em ambientes virtuais de aprendizagem, assim como a criação de novas ferramentas a fim de aumentar o interesse dos estudantes acerca de diferentes e infinitas temáticas. 


\section{Referências}

[1] ALBUQUERQUE, R.M.; AZEVEDO, V.A.; CRUZ, D.M. Jogos eletrônicos na escola: uma experiência educativa com o LinCity-NG, VIII Brazilian Symposium on Games and Digital Entertainment. Rio de Janeiro. 2009.

[2] ALVES, L.; GUIMARÃES, H.; OLIVEIRA, G.; RETTORI, A. Ensino On-Line, jogos eletrônicos e RPG: Construindo novas lógicas. Conferência eLES'04, Aveiro-Pt, 2004.

[3] ARANHA, G. Jogos Eletrônicos como um Conceito Chave para o Desenvolvimento de Aplicações Imersivas e Interativas para o Aprendizado. Revista Eletrônica Ciência e Educação, v.7, p.105-110, ISSN: 1806-5821, 2006.

[4] AUGUSTIN, I. et al. ISAM, joining context-awareness and mobility to building pervasive applications. Mobile Computing Handbook. Ed. Florida. 2004

[5] BALASUBRAMANiAN, N.; WILSON, B. G. Games And Simulations. In: Society for Information Technology and teacher Education International Conference, 2006. Proceedings...v.1. 2006. Disponível em: $<$ http://site.aace.org/pubs/foresite/GamesAndSimulations1.pdf>. Acesso em: dez. 2007.

[6] BARReto, A. A. A questão da informação: São Paulo em Perspectiva. São Paulo, [s.n], 1994. Disponível em: <http://www.alternex.com.br/ aldoibict/quest/quest.htm>. Acesso em: fev. 2008.

[7] ECK, R. V. Digital Game-Based Learning: It. Educase Review, v.41, n.2, p.16-30,mar.2006. Disponível em: $<$ http://www.educause.edu/apps/er/erm06/erm0620.asp>. Acesso em: out. 2011

[8] ELMAN, L. E.; WERBA, A. Pré-escola no mundo do computador. Revista do Professor. Porto Alegre, v.10, n.37, jan./mar. 1994.

[9] FORTUNA, T. R. Sala de aula é lugar de brincar? In: XAVIER, M.L.F. e DALLA ZEN, M.I.H. Planejamento: análises menos convencionais. Porto Alegre: Mediação, 2000 (Cadernos de Educação Básica, 6), p.147-164.

[10] FREIRE, P. Ação cultural para a liberdade. Rio de Janeiro: Paz e Terra, [s.n], 1996.

[11] GROS, B.. The impact of digital games in education. First Monday, v.8, n.7, jul. 2003. Disponível em: $<$ http://www.firstmonday.org/issues/issue8_7/xyzgros/index.html>. Acesso em: out. 2007.

[12] HAETINGER, M. Informática na Educação: Um Olhar Criativo, Coleção Criar. vol. 02 - Instituto Criar Ltda. 2003.

[13] MITCHELL, A.; SAVILL-SMITH, C. The use of computer and video games for learning: a review of the literature. Londres: Learning and Skills Development Agency (LSDA), 2004. Disponível em: $<$ http://www.lsda.org.uk/files/PDF/1529.pdf>. Acesso em: set. 2008.

[14] OLIVEIRA, L.C.; MOZZAQUATRO, P.M. Estudo sobre Cloud Computing: um novo paradigma para ELearning e M-Learning. XVI Seminário Interinstitucional de Ensino, Pesquisa e Extensão. Universidade de Cruz Alta (UNICRUZ), 2011.

[15] OLIVEIRA, L.; MARTINS, T.; SCHWADE, D.E.; LINCK, I.M.D. A relação entre a teoria e a prática na utilização da informática no contexto escolar. XII Seminário Internacional de Educação no Mercosul. Cruz Alta - RS, 2010.

[16] SYVÄNEN, A. et al.. Accessibility And Mobile Learning. In: IFIP ETRAIN CONFERENCE IN PORI, Finlândia, 2003.

Revista Brasileira de Computação Aplicada (ISSN 2176-6649), Passo Fundo, v. 4, n. 2, p. 92-102, out. 2012101 
[17] VALENTE, J. A. O Uso Inteligente do Computador na Educação. [S.1.:s.n],[2002]. Disponível em: <http://www.proinfo.gov.br/biblioteca/textos/txt/usoint.pdf>. Acesso em: mar. 2008

[18] XU, Huaxiang. The influence of Cloud computing on education. Computer knowledge and technology, v.5, n.4, p.2690-2692, 2009.

[19] WEISER, M. The Computer for the 21st Century. Scientific American, 1991, p. 94 - 104. 